\title{
Erratum to: A new strain of Bjerkandera sp. production, purification and characterization of versatile peroxidase
}

\author{
Roberto Taboada-Puig • Thelmo Lú-Chau • \\ María Teresa Moreira • Gumersindo Feijoo • \\ María Jesús Martínez $\cdot$ Juan Manuel Lema
}

Published online: 26 May 2011

(C) Springer Science+Business Media B.V. 2011

\section{Erratum to: World J Microbiol Biotechnol (2011) 27(1):115-122 \\ DOI 10.1007/s11274-010-0435-2}

Unfortunately, in the above-mentioned article, the two following corrections should be included.

1. In the section "Materials and methods", the end of the subsection "Fungal strain and culture conditions" should read as:

The fungal strain used in this work was isolated in South Chile and provided to us by the Laboratory of
Environmental Biotechnology of Universidad de la Frontera (Temuco, Chile), classified as Anthracophyllum discolor.

2. The Acknowledgement section should include the following text:

The authors also thank the Laboratory of Environmental Biotechnology of Universidad de la Frontera (Chile) for providing the fungal strain used in this work.

The online version of the original article can be found under doi:10.1007/s11274-010-0435-2.

R. Taboada-Puig · M. T. Moreira $(\bowtie) \cdot$ G. Feijoo $~$ J. M. Lema Department of Chemical Engineering, School of Engineering, University of Santiago de Compostela, 15782 Santiago de

Compostela, Spain

e-mail: maite.moreira@usc.es

T. Lú-Chau

Department of Chemical Engineering, Institute of Technology,

15706 Santiago de Compostela, Spain

M. J. Martínez

Centro de Investigaciones Biológicas, Consejo Superior de Investigaciones Científicas, Ramiro de Maeztu 28040 Madrid, Spain 